\title{
Cândido de Abreu: projetos do primeiro urbanista da cidade de Curitiba do início do século XX
}

\author{
Cândido de Abreu: Projects of the first \\ urbanist of Curitiba in early 20th century
}

Marcus Levy Bencostta*

\section{Resumo}

A reflexão que proponho trata de algumas questões relacionadas à importância da arquitetura e do espaço por ela determinado como portadores e transmissores de linguagens e sentidos múltiplos acerca do universo urbano. Privilegiarei, portanto, o discurso arquitetural de Cândido de Abreu, considerado o primeiro urbanista da cidade de Curitiba. Ele ficou mais conhecido por seus projetos de construção de praças e jardins, solares e edifícios públicos e, pouco menos, como autor do projeto de construção do edifício do Grupo Escolar Dr. Xavier da Silva, inaugurado solenemente no final de 1903. Procuro demonstrar por meio de pesquisa histórica as principais referências arquiteturais desse engenheiro como suporte de compreensão de uma cultura urbana e escolar que toma como exemplo o edifício do primeiro grupo escolar do estado do Paraná. Palavras-chave: Arquitetura; História; educação.

\section{Abstract}

The reflection that I propose deals with some issues on the importance of architecture and the space which it determines as carriers and conveyors of multiple languages and meanings in the urban universe. I will emphasize the architectural discourse by Cândido de Abreu, considered the first urban planner in Curitiba. He is best known for his projects of squares and gardens, manor houses and public buildings, and a little less known for being the author of the project for the school building called Grupo Escolar Dr. Xavier da Silva, solemnly inaugurated in the end of 1903. I intend to demonstrate the most important architectural references of that engineer by means of a historical research as comprehension support for an urban and school culture that considers the building of the first school in Parana state as an example.

Keywords: Architecture; History; education.

\footnotetext{
* Universidade Federal do Paraná (UFPR). Núcleo de Estudos e Pesquisas em História da Arquitetura Escolar (NEPHArqE). Curitiba, PR, Brasil. marcus@ufpr.br ${ }^{1}$
} 
Nas últimas décadas, as diversas questões multidisciplinares apresentadas por pesquisadores e profissionais dos mais variados campos de atuação das Ciências Humanas demonstram como tem sido rico o debate sobre a cultura material e os desafios que a ela têm sido postos pela realidade contemporânea (Bencostta, 2013a). É, portanto, nos espaços privilegiados de discussão desses pesquisadores - fóruns, seminários, congressos e publicações - que se conhece um conjunto de novas metodologias de investigação e estratégias políticas de guarda e preservação do patrimônio cultural. Esse conjunto de práticas e experiências reafirma o alerta que a academia e a sociedade devem ter frente aos assuntos que envolvem as polêmicas sobre o patrimônio cultural.

No bojo dessa discussão, é fácil observar a importância das ações que garantem minimamente a integridade dos bens materiais culturais nas novas formas de entendimento dos vínculos existentes entre cidade e cultura, o que tem colaborado para se compreender a noção de patrimônio no campo dos estudos culturais (Bencostta, 2013a).

No campo da História da Educação, cada vez mais a produção tem identificado e analisado objetos escolares, livros didáticos, edifícios e equipamentos diversos, utilizando a noção de "cultura material escolar" para trabalhar suas interpretações. Para evitar o risco de naturalizar essas abordagens, padronizando-as, essa produção busca se esquivar de anacronismos que recorrem a essa noção apenas para explicar diferentes contextos que marcaram profundamente a historicidade da escola.

Quando os historiadores da educação começaram a enxergar a escola como um "lugar de memória" na concepção defendida por Pierre Nora (1984; 1986; 1992), que o explica como local material ou imaterial no qual se cristalizam as memórias de uma nação e onde se cruzam memórias pessoais, familiares e de grupo, foram surpreendidos com a necessidade de compreendê-la como parte de um conjunto de representações e linguagens semânticas construídas e manifestadas no tempo e no espaço histórico.

$\mathrm{O}$ amadurecimento dessa noção ganha reconhecimento, dentro e fora da História da Educação, enquanto cresce o envolvimento de investigadores comprometidos na construção de contribuições teóricas e fundamentações conceituais referenciadas pelo pensamento histórico, independentemente da sua matriz. Essa história dos usos dos objetos escolares e de sua relação com a cultura material reconhece o seu valor investigativo como resultado de reflexões que não se limitam a um olhar que nela enxerga uma discussão em separado dos fenômenos próprios da historiografia educacional. 
Neste ponto, devemos fazer uma pausa e pensar nas contribuições e articulações que os estudos sobre a cultura material escolar oferecem à rede de problematizações que a História da Educação propõe na explicação dos fenômenos educacionais, e com isso evitar que elas sirvam apenas para confirmar conclusões que as demais fontes anunciam, descompasso flagrante que lhe sugere de modo explícito um papel coadjuvante no debate historiográfico. A cultura material escolar é um construto histórico, produto da experiência humana com usos que se modificam de acordo com os sentidos e significados que os diferentes contextos educacionais produzem. Por isso, também, sua investigação deve se preocupar com as ressignificações e ressemantizações, que não restrinja suas análises apenas à história do objeto material para fins escolares. Junto à objetividade desse objeto estão presentes componentes subjetivos originários dos contextos de sua produção e consumo, o que nos aproxima definitivamente da noção de Jacques Le Goff (1984) de que esses também podem ser compreendidos como documento/monumento. As formas de organização dos objetos escolares frente aos processos de apropriação pelo universo escolar e as representações sociais decorrentes das suas práticas materiais nos ajudam a compreender a cultura material escolar nos aspectos fundamentais da análise histórica.

Todo nosso empenho metodológico de propor uma síntese conceitual à noção de cultura material escolar esbarra na necessidade de compreendê-la nas condições exigidas pela escrita da história na construção dos sentidos própria à sua explicação sobre o passado. O esforço de compreender aquilo que é essencial e relevante na cultura material escolar não permite, entretanto, decalcá-la ou muito menos isolá-la de outros elementos conceituais da cultura, apesar de suas especificidades. Essa questão não deve ser vista como menor no trabalho de construção de uma narrativa histórica, de uma escrita que permita explicar de modo inteligível o argumento em defesa. Não que esteja falando qualquer novidade, mas essa escrita nos alerta para o cuidado que devemos ter com a precisão de nossos métodos de análise e do trato com as fontes perante as lacunas e as brechas presentes na historiografia da educação brasileira, ausências, silêncios e não ditos que nos estimulam e nos impulsionam ainda mais no ofício de pesquisadores.

Para a análise dos significados sociais da escola é preciso observar e discernir os discursos dos sujeitos e de suas fontes com o objetivo de estabelecer pertinências entre os conhecimentos transmitidos por uma tradição específica, a cultura material escolar, e outra mais extensa que o da cultura, responsáveis por revelar regularidades, rupturas, deformações e ambiguidades no 
comportamento e na experiência humana. É nesse sentido que convido os leitores a trilharem o percurso investigativo deste artigo utilizando a trajetória e a experiência do arquiteto Cândido Ferreira de Abreu e sua contribuição para a cultura material curitibana no início do século XX.

\section{CÂNdido Ferreira de AbreU: fragmentos BIOGRÁFICOS (1885/6-1916)}

Na historiografia memorialista dos atores da cena política paranaense (Westphalen, 1959; Carneiro, 1963; Leão, 1994; Hoesner Júnior, 2002; Dicionário, 1991), Cândido de Abreu é identificado de forma bastante laudatória.

Originário da cidade portuária de Paranaguá (alguns datam o ano de seu nascimento em 1855; outros, em 1856), era neto por parte de mãe do Visconde de Nácar (Manoel Antônio Guimarães, um dos mais bem-sucedidos comerciantes exportadores de erva-mate do século XIX e dono da maior casa importadora do Paraná). Contudo, a precoce orfandade de Cândido o privou da sorte das demais crianças que pertenciam à elite ervateira paranaense, visto que seu pai (Antonio Ferreira de Abreu) deixou como herança diminutas posses para os seus filhos. Apesar das dificuldades financeiras que sua família enfrentou, Cândido conseguiu concluir os estudos primários em sua cidade natal, para logo em seguida partir para a capital da Província, Curitiba, onde deu entrada nos estudos secundários. A conclusão dessa etapa de sua formação aconteceu na cidade do Rio de Janeiro, em 1874. E foi na Corte do Império que ele decidiu pela carreira de engenheiro, ao realizar seus estudos na Escola Polytechnica do Rio de Janeiro (1879-1882).

Durante os anos de estudos superiores, além do conhecimento técnico das engenharias e da arquitetura, o ambiente intelectual da Polytechnica e da cidade do Rio de Janeiro contribuiu em sua formação, influenciando o jovem mancebo paranaense nas correntes do pensamento positivista e nas ideias republicanas, marcas que o acompanharam nos anos vindouros dedicados à política e à administração pública.

De posse de sua habilitação de engenheiro, entre 1884 e 1885 trabalhou na polêmica construção da Estrada de Ferro Madeira-Mamoré, na longínqua, perigosa e ainda pouco conhecida Amazônia - foi esse o seu début na vida profissional. Antes do finalizar a obra desse empreendimento, Cândido de Abreu retornou à Corte, em 1885, onde permaneceu na burocracia do Ministério da 
Agricultura até partir para assumir o cargo de Inspetor de Colonização na outra ponta do Brasil - o Rio Grande do Sul.

Após 13 anos longe de casa, aceitou o convite do próprio presidente da província do Paraná para assumir aquele que seria o seu primeiro cargo de grande envergadura: Diretor de Obras Públicas da Província do Paraná (1887-1889).

Com a implantação do regime republicano, Cândido de Abreu soube permanecer nos palcos políticos e gabinetes da administração pública paranaense. Certamente a República abriu-lhe possibilidade para iniciar sua carreira política, carreira esta marcada por altos e baixos. Primeiramente, foi indicado mais uma vez para a Secretaria de Obras Públicas (antiga Direção de Obras Públicas), durante o primeiro mandato de Francisco Xavier da Silva (Relatório, 1892).

Sua atuação enquanto administrador, assim como a relação que mantinha com importantes personagens da política paranaense, fizeram-no lançar-se candidato às eleições municipais no novo regime, e, vencido o pleito em 1892, tornou-se o primeiro prefeito eleito da cidade de Curitiba.

Sua permanência na mais alta cadeira da capital do estado foi de apenas 11 meses, até anunciar publicamente sua renúncia ao cargo de prefeito. Essa situação em parte se explica por sua insatisfação com os camaristas municipais, mas também por sua inabilidade no jogo político.

Entre suas ações antes da renúncia destacam-se a instalação da energia elétrica no centro da cidade e a revisão do devassado Código de Posturas de Curitiba, medidas que sinalizavam os ventos da modernização se aproximando com a chegada do século XX.

Republicano convicto e fiel ao presidencialismo, por sua lealdade foi nomeado pela União, em 1894, tenente coronel honorário do Exército nacional, resultado do seu apoio a Floriano Peixoto na Revolução Federalista.

Nos anos em que permaneceu fora da política, Cândido de Abreu retornou ao ofício de engenheiro e participou da importante Comissão de Planejamento da cidade de Belo Horizonte, oportunidade ímpar de trabalhar como membro da equipe do urbanista Aarão dos Reis, entre 1895 e 1896. O período em Minas Gerais contribuiu para sua maturidade como arquiteto e urbanista, de modo que não é possível vê-lo apenas como engenheiro, sua característica mais forte no início de sua carreira, mas a confluência das três. Será esse "novo" Cândido que retornará mais uma vez a Curitiba para assumir o espaço administrativo que melhor soube aproveitar para desenvolver suas ideias: a Secretaria de Negócios das Obras Públicas e Colonização (1896-1899) no governo de José Pereira Santos Andrade (Relatório, 1896). 
Sua adesão ao republicanismo e os laços de amizade com a elite política paranaense (Vicente Machado, Carlos Cavalcanti, Santos Andrade, Ubaldino do Amaral, Victor Ferreira do Amaral e Xavier da Silva) o conduziram às eleições gerais no estado (deputado, 1901-1903) e na sequência para o Congresso Nacional (deputado federal, 1903-1905; senador, 1906-1914). Durante seu mandato como senador, a política curitibana se agitava nas discussões sobre quem deveria ocupar a cadeira de prefeito, escolha que se tornou atribuição pessoal do governador do estado, naquela ocasião Carlos Cavalcanti. Usando de suas prerrogativas, o chefe do Executivo decidiu que caberia ao senador Cândido de Abreu assumir a titularidade do poder municipal, ocupada interinamente pelo camarista mais votado nas últimas eleições (A República, 18 set. 1912).

De volta à prefeitura em 1913, foi esse o último cargo político de sua vida, pois veio a falecer em Curitiba em 1916.

Não desmerecendo sua trajetória política, o que de antemão provocaria um rico debate no campo da história, nas próximas páginas minha opção é utilizar alguns fragmentos desse personagem, enquanto engenheiro e arquiteto, na tentativa de entender e explicar seus projetos do ponto de vista das concepções que determinaram suas ideias acerca da importância da arquitetura. Fazendo desse modo, acredito ser possível problematizar algumas questões sobre sua linguagem e referências arquiteturais, cuja finalidade é propor uma compreensão da experiência que terá no seu percurso a incumbência de projetar o edifício do primeiro Grupo Escolar do Paraná. Entretanto, considero interessante que o leitor conheça um pouco das edificações projetadas por esse arquiteto, antes de detalhamos sua vinculação com a arquitetura escolar.

\section{UM OLHAR PARA A ARQUITETURA RESIDENCIAL: \\ OS DESEJOS DAS ELITES PELOS PALACETES (1897-1906)}

O enriquecimento das elites ervateiras no período compreendido como Belle Époque curitibana (fim do século XIX e início do XX) exacerbou uma preocupação que já as incomodava havia algum tempo - queriam uma moradia que se diferenciasse daquela dos casarões e chácaras do início do século XIX. Mesmo que continuasse sendo um espaço familiar, a casa também deveria ser um novo espaço de convivência política e cultural urbana, ornado com traços arquiteturais europeizantes dos palacetes e solares de linhas ecléticas. Com esse intuito, os senhores do mate contrataram arquitetos brasileiros e estrangeiros sintonizados com as últimas tendências de cunho moderno, em 
especial italianos, alemães e franceses, adeptos do que hoje denominamos ecletismo, por acreditarem ser essa uma linguagem que se anunciava no Brasil como a última vanguarda que vinha do mundo civilizado.

Polêmicas à parte sobre o papel do ecletismo na arquitetura urbana brasileira, o certo é que vários escritórios de arquitetura adotaram esse tipo de gramática para atender os anseios das elites brasileiras que se espelhavam nas elites estrangeiras, em especial aquelas do ocidente europeu. Em São Paulo, por exemplo, foi contundente para a mudança da paisagem urbana a ação de Ramos de Azevedo na difusão desse estilo. ${ }^{2}$ Dentre esses arquitetos e engenheiros, Cândido de Abreu se destaca por sua contribuição na propagação do ecletismo em Curitiba, em especial, nos projetos que desenhou para residências de parentes e amigos da elite da capital paranaense.

O primeiro exemplo é o palacete encomendado pelo ervateiro Ascânio Miró (Figura1). Essa bela residência foi erguida na antiga Estrada do Mato Grosso, região do atual bairro Batel, uma das preferidas para casas monumentais que atendiam as elites locais curitibanas, longe dos infortúnios do centro da cidade. Quando projetou e construiu o Palacete Ascânio Miró, entre 1897 e 1898, Cândido de Abreu estava no exercício do cargo de secretário de Obras Públicas do governador Pereira Passos.

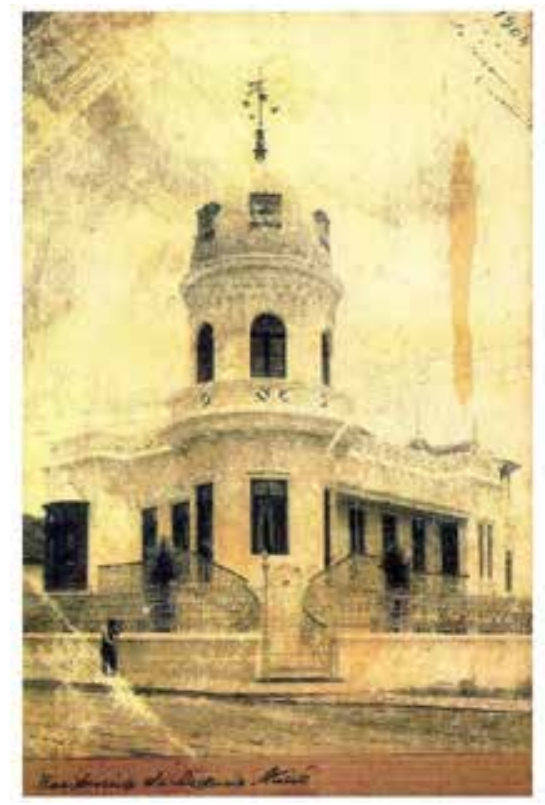

Figura 1 - Palacete Ascânio Miró Acervo: Casa da Memória/Curitiba. 
Com esse exemplo é possível perceber elementos que ressaltam a linguagem do estilo adotado, como o torreão cilíndrico que cumpre a função de organizar toda a gramática eclética de sua linguagem arquitetônica, o que valorizou a esquina onde foi edificado (designação atual como rua Comendador Araújo esquina com a rua Presidente Taunay). Também o uso do ferro batido para compor as varandas laterais fica por conta da influência de certa modernização na forma de construir utilizando diferentes materiais.

A sofisticação e a imponência que compõem sua fachada também estiveram presentes no interior dessa residência.

Os requintes no interior do palacete eram dados com os tetos de estuque decorados de forma diferente em cada compartimento e com ornamentação variando conforme o ambiente. Destacavam-se na sala de jantar, nos quatro cantos, anjos trepados em macieiras, guirlandas ao redor do lustre de cristal completavam os ornamentos. Na sala de visitas, a pintura representava rosas e, na saleta, flores miúdas. (Mendonça, 1975, p.3)

Passados mais de cem anos desde a sua construção, precisamente no ano 2000, tem início na imprensa uma campanha de conscientização para impedir a paulatina demolição de parte do casario localizado na rua Comendador Araújo pela especulação imobiliária que assolou aquele lado da cidade (Gazeta do Povo, 13 jun. 2000). Um dos resultados dessa campanha foi a ação do Conselho Estadual do Patrimônio Histórico Artístico (Cepha) do Paraná que levou adiante o processo de tombamento da paisagem urbana daquela região. A decisão final se deu em reunião extraordinária do Cepha, em abril de 2004, que tornou o palacete de Ascânio Miró, com outros 37 casarões, Unidades de Interesse de Preservação (Diário Oficial do Paraná, 17 mar. 2004). Essa decisão foi posteriormente sacramentada pelo Ofício no 259/03 da Coordenação do Patrimônio Cultural da Secretaria de Cultura do Paraná que anunciou a decisão do Cepha (Termo de Encerramento, 2004). Atualmente, o palacete é patrimônio do Banco Itaú Unibanco, e lá funciona uma de suas agências.

Cândido de Abreu continuou atendendo o mesmo grupo econômico e familiar. O segundo exemplo (Figura 2) é o palacete que desenhou para o cunhado e ervateiro espanhol Manoel Miró (irmão de Ascânio Miró), que nomeou a construção. Esse projeto iniciou-se logo após a saída do governo de Pereira Passos, em 1900, e foi entregue à família Miró 2 anos depois, quando ainda exercia o mandato de deputado estadual. ${ }^{3}$ 


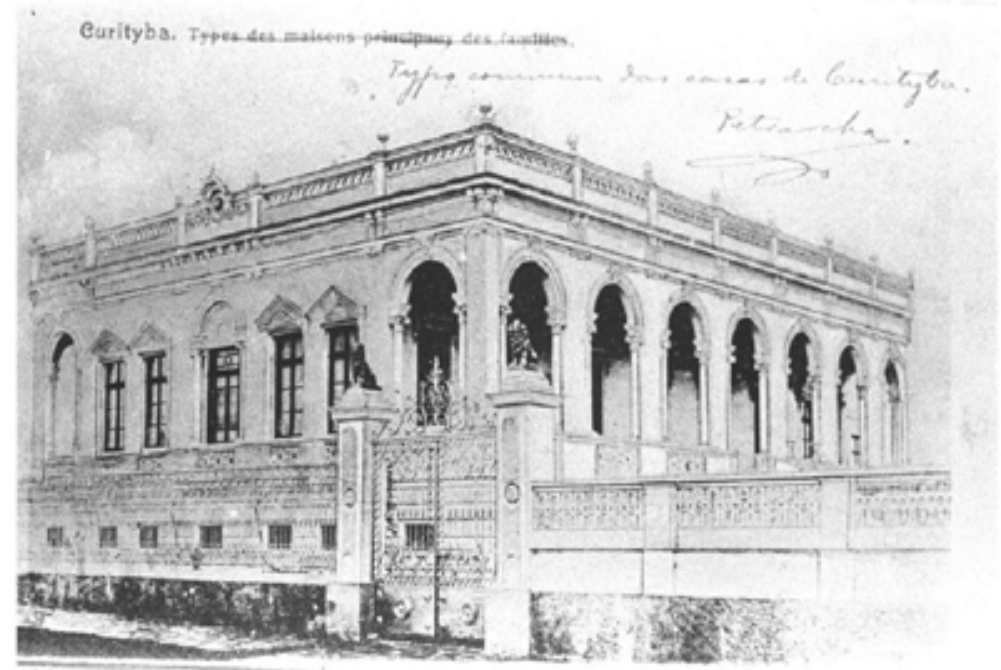

Figura 2 - Palacete Manoel Miró

Acervo: Casa da Memória/Curitiba.

Notadamente a opção pelo ecletismo se manifesta na adoção da simetria do seu volume, no uso das linhas ornamentais e adereços na sua elevação (fachada). Um gradil e portão trabalhados em ferro e um muro separavam a esfera privada do palacete da rua Comendador Araújo. ${ }^{4} \mathrm{O}$ exíguo espaço frontal levou Cândido de Abreu a adotar a solução pelo jardim lateral como forma de garantir um local de lazer e requinte à família Miró e convidados nas manhãs e tardes ensolaradas. Os alpendres ressaltados por arcos que destacam as entradas laterais também se tornaram um símbolo das residências de elite.

Concomitante à construção do Palacete Manoel Miró, a outra irmã de Cândido de Abreu (Maria Clara de Abreu Leão), com seu esposo, o ervateiro Agostinho Ermelino de Leão Júnior, solicitaram-lhe um projeto de residência. Continuando na mesma rede de sociabilidades, o terceiro exemplo é o mais refinado palacete projetado por Cândido de Abreu (Figura 3).

Entregue à família Leão em 1902, mesmo ano do palacete da família Miró, está localizado no Boulevard Dois de Julho (atual rua João Gualberto) no bairro Alto da Glória, outra área bastante procurada e valorizada para as residências da elite ervateira.

Dotado de porão habitável, com ampla escadaria em mármore levando à entrada principal, onde há uma sucessão de portas em arco pleno, intercaladas por pilas- 


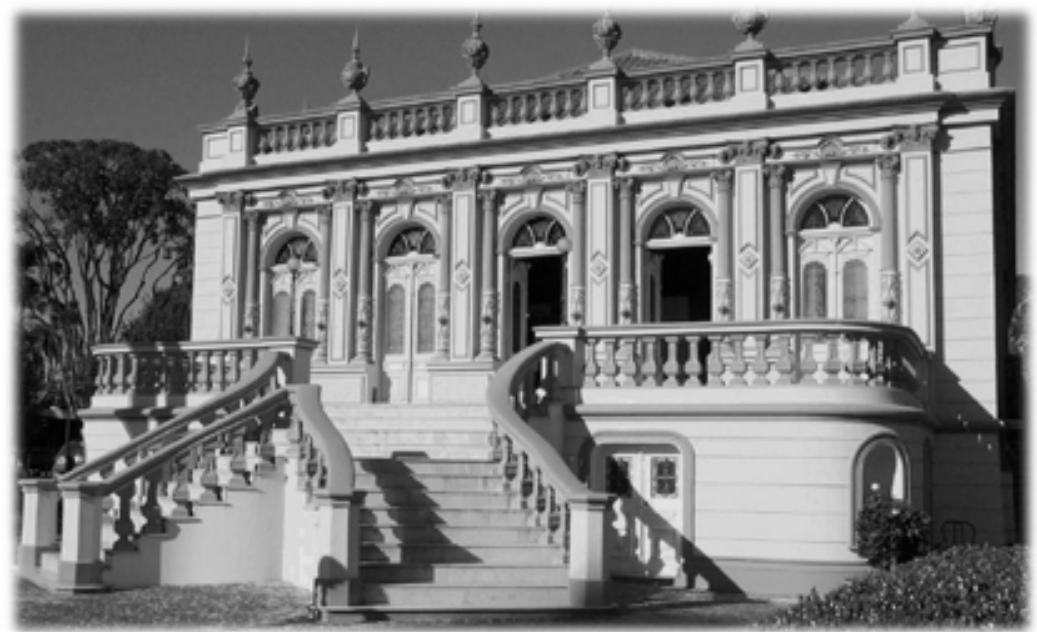

Figura 3 - Palacete Leão Júnior

Acervo: IBM.

tras, a construção adquiriu um ar palaciano, em muito favorecido pelos jardins que a cercam e pelos pináculos em forma de jarro, dispostos sobre a platibanda. A simetria marca suas formas, e a inspiração de Cândido de Abreu, para o projeto, foi renascentista, permitindo, porém, em alguns momentos, manifestações barrocas. No auge e fausto da economia ervateira, a residência de Leão Júnior foi considerada um dos mais modernos e requintados solares de Curitiba; os recursos plásticos empregados e a monumentalidade da construção eram até então inéditos. (Sutil, 2009, p.5)

Considerada pela imprensa como uma peça arquitetônica de sobrelevado interesse, o Palacete dos Leões esteve presente nas páginas dos jornais quando noticiavam acontecimentos fugazes dos mais diversos da sociedade curitibana que ali aconteciam, como por exemplo, quando nele ficou hospedado o presidente da República e parte de sua comitiva em visita ao Paraná.

O nosso prestigioso amigo Sr. Capitão Agostinho Ermelino de Leão e sua Exma. Família, que tão fidalgamente cederam seu luxuoso palacete para a instalação do Sr. Afonso Penna e de algumas ilustres pessoas de sua companhia, foi um extraordinário obséquio que jamais será olvidado. (A República, 9 ago. 1906)

Ao cabo de 10 anos (1897-1906), a experiência de Cândido de Abreu como projetista de residências nobres obrigou-o a racionalizar sua agenda de 
arquiteto com a de político, dividido entre a prancha de desenho de seu escritório, a escrivaninha do cargo de diretor geral de Obras Públicas do Estado do Paraná e os palanques que utilizou para os seus discursos durante os mandatos de deputado estadual e senador da República.

Depois de entregues os palacetes da família Miró (Ascânio e Manoel) e Leão Júnior, chegou a vez de projetar a Casa das Ferraduras, ${ }^{5}$ solar que desenhou para si e sua família, em 1906.

Próxima ao palacete da irmã (também no Boulevard Dois de Julho, Alto da Glória), o estilo que encontrou para a Casa das Ferraduras (Figura 4) foi diferente daquele adotado nos palacetes.

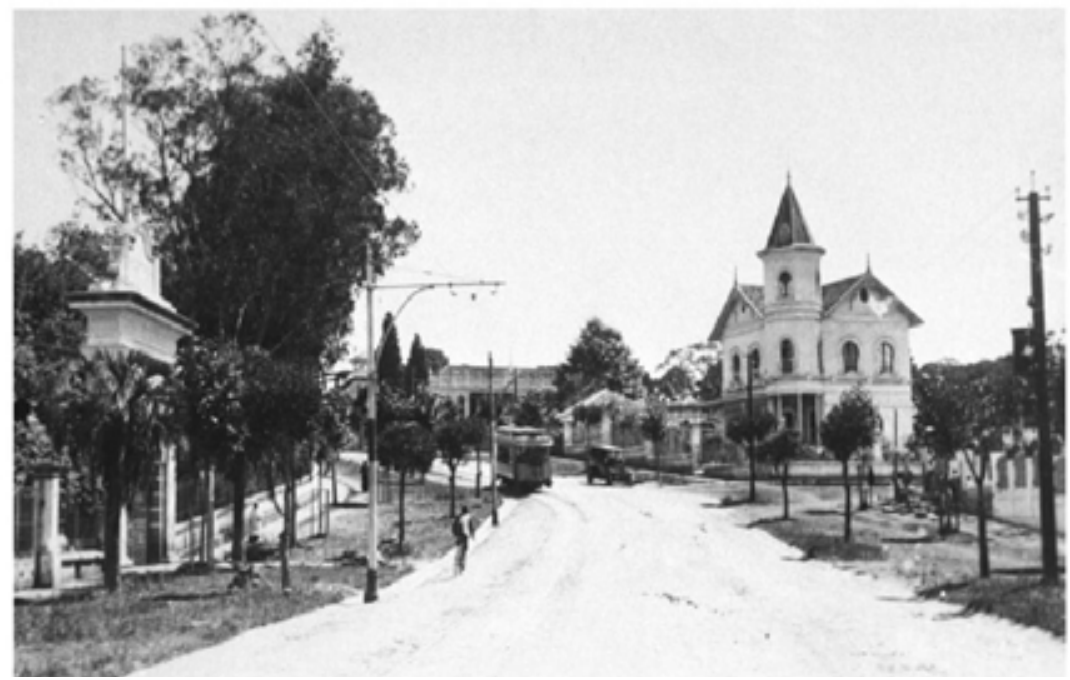

Figura 4 - Casa das Ferraduras

Acervo: Casa da Memória/Curitiba.

Desta vez sua morfologia emprega algumas características ornamentais e decorativas do Art Nouveau, especialmente vistos no desenho das janelas e nos recortes do portão de acesso à casa. Por um olhar, os telhados com inclinação acentuada lembram a arquitetura dos chalés europeus, mas por outro, o torreão octogonal medievalístico sugere uma leitura que imita a torre de um castelo, cuja função será semelhante àquela observada no Palacete Manuel Miró, de organizar as elevações laterais e os pisos que compõem a edificação. 
UM OLHAR PARA A ARQUITETURA PÚBLICA:

o Paço Municipal de Curitiba (1914-1916)

Se com a Casa das Ferraduras Cândido de Abreu utilizou pela primeira vez alguns poucos traços do Art Nouveau em sua arquitetura, foi com o projeto do Paço Municipal (Figura 5) e com o Belvedere ${ }^{6}$ que esse uso foi profundamente adotado em sua semântica. A encomenda havia sido um pedido pessoal do governador Carlos Cavalcanti, e o local para o novo palácio do governo municipal (prefeito e camaristas) deveria ser a praça Generoso Marques, exatamente onde estava instalado o Mercado Municipal que teve de ser transferido provisoriamente para a praça Dezenove de Dezembro. O Paço foi construído entre 1914 e 1916, período em que foi nomeado prefeito da cidade, desta vez em seu segundo mandato.

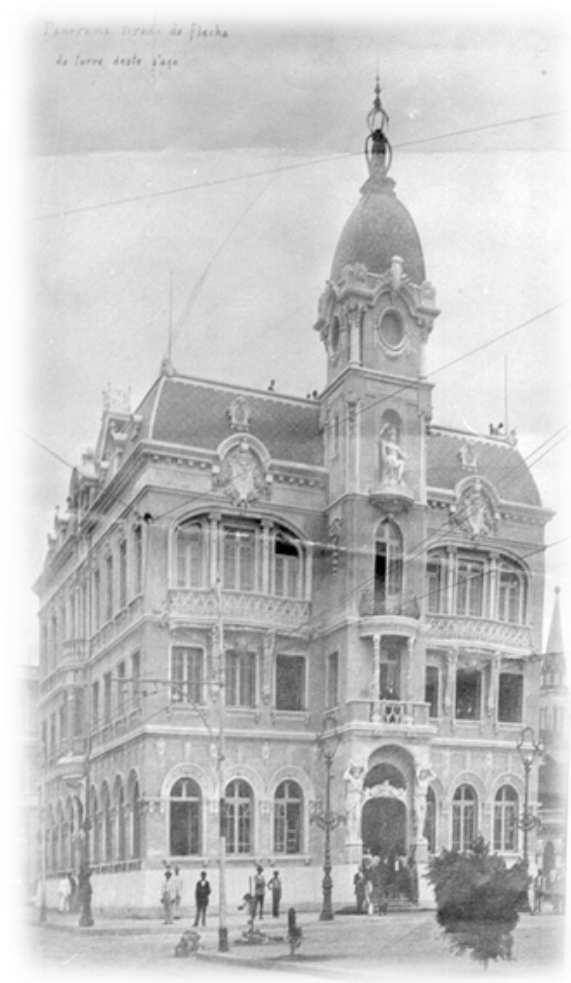

Figura 5 - Paço Municipal de Curitiba Acervo: Casa da Memória/Curitiba. 
As referências ao Art Nouveau nesse edifício são múltiplas e diversas, perceptíveis desde a sua fachada e adentrando em seu interior. ${ }^{7}$ Os elementos decorativos - guirlandas, ninfas, caneluras e ornamentos orgânicos no gradil - estão espalhados por toda a obra. No mês anterior à sua inauguração oficial (24 de fevereiro de 1916), Cândido de Abreu abriu excepcionalmente o prédio para uma visita guiada aos jornalistas, com o objetivo de apresentar o resultado do empreendimento. Vejamos breve trecho de um desses relatos sobre o novo Paço Municipal:

Conforme já temos noticiado a inauguração do elegante palácio deverá ser realizada no próximo dia 24 de fevereiro, data da Promulgação da Constituição Federal ... o aspecto geral externo é grandioso; as fachadas têm o cunho da elegância impressionante onde a vista se entretém sem cansaço a admirar a nota artística que o gênio esculpiu e modelou em uma plástica de real merecimento. Os degraus são talhados em bom granito. Os Hércules que fingem suportar a torre estão realmente majestosos. Na torre, a figura central que é de uma bela jovem, tendo vestido peplum e túnica, e que se encontra assentada, representa a cidade de Curitiba, presidindo aos destinos do seu povo e cuja execução é digna de merecimento. Completa a ornamentação da torre, um escudo com as armas do município, cabeças de leão, símbolos de força; a cúpula de superfície curvilínea coberta a eternite e sobre esta um foco de luz elétrica com a intensidade de mil velas ... Nas diversas frentes há mais a notar os 2 bouvoirs $^{8}$ laterais de forma semicircular e cuja ornamentação está corretamente disposta. A marquise colocada na fachada posterior de forma elíptica é toda coberta com vitraux de um efeito agradável. (Diário da Tarde, 17 jan. 1916, p.1)

Segundo o Diário da Tarde, para a execução do projeto do Paço Municipal contratou-se uma equipe formada por vários profissionais: os trabalhos de marcenaria ficaram sob a responsabilidade dos artesãos da oficina Maderna \& Bonne; o arquiteto paulista Roberto Lacombe esculpiu os ornamentos e as estátuas decorativas; artistas portugueses e italianos trataram das cantarias; o curitibano João Guelffi e o italiano João Ortolani criaram as pinturas que enfeitam o interior. A supervisão geral era de responsabilidade direta de Cândido de Abreu, entretanto, seu cargo de prefeito pedia outros assuntos, de modo que o auxiliou nessa empreita o engenheiro Adriano Goulin. Delegou-se aos arquitetos Angelo Bottechia e André Petrelli a direção dos trabalhos (Diário da Tarde, 18 jan. 1916, p.1). 
Na interpretação da linguagem empregada no Paço Municipal de Curitiba, a partir da noção de espaço discursivo decorrente das preocupações epistêmicas de Michel Pêcheaux, em especial daquelas de seus últimos escritos, é possível admitirmos a circulação de diferentes sentidos e formações discursivas de apreensão daqueles sujeitos que conviviam e interagiam com a arquitetura de edifícios para uso da máquina pública, distanciando-se, portanto, de uma única forma de enxergar e interpretar os referentes e os dispositivos linguísticos que lhe dizem respeito. Nesse sentido, para concluir este item, nos ajuda Pêcheaux quando aborda as condições de produção discursiva ao afirmar que "todo o enunciado é intrinsecamente suscetível de tornar-se outro, diferente de si mesmo, se desloca discursivamente de seu sentido para derivar para um outro" (Pêcheaux, 1997, p.53).

\section{UM OlHAR PARA A Arquitetura Escolar: \\ o Grupo Escolar Dr. Xavier da Silva (1903)}

Dentre os vários objetos que emergem das investigações acerca da cultura material escolar, um que tem contribuído para o avanço da pesquisa histórica nesse campo é o próprio edifício que abriga a instituição educacional (Bencostta, 2013a). Para além da importância de tais edifícios projetados e/ou utilizados para fins educacionais terem sido artefatos plenamente incorporados ao universo da cultura material escolar, é preciso problematizar os discursos gerados pelas linguagens arquitetônicas que auxiliam na construção de explicações acerca da historicidade dos usos e das funções do edifício escolar.

Podemos enxergar em tais estudos como se deu a construção de novos edifícios específicos para as escolas primárias públicas espalhadas pelo Brasil republicano, o qual investiu no urbano como o espaço privilegiado para a sua edificação. Para valorizar a escala arquiteturológica geográfica e de visibilidade, sua localização deveria funcionar como ponto de destaque na cena urbana, enquanto signo de ideal republicano de uma gramática discursiva arquitetônica que enaltecesse o novo regime.

Assim, a cultura material escolar faz parte de uma estrutura teórica mais ampla, com largas potencialidades para a investigação histórica. Nesse sentido, os estudos que tratam da cultura material escolar têm conquistado paulatinamente seu espaço de reconhecimento na historiografia educacional brasileira:

em boa parte viceja no ecletismo das teorias, recompondo quadros de entendimento do nacional referenciados por literatura estrangeira. Não diríamos, como 
alguns autores, que estamos presos a um cenário de colonização do pensamento. Ao contrário, acreditamos que o ecletismo de nossa produção espelha os limites da incorporação da bibliografia internacional, constituída por trajetórias sócio-históricas específicas e na resposta a problemas de pesquisas singulares de cada uma das realidades históricas tomadas. Nesse sentido, parece-nos, no amadurecimento das fusões estabelecidas e no enfrentamento ao desafio de teorizar "em português" caminharemos para o desejável movimento de elaboração de referenciais, construídos no diálogo com autores de outros países, sim, mas assentados em problemáticas que nos são específicas. (Bencostta; Vidal, 2010, p.300)

A respeito da criação dos grupos escolares no Brasil, suas origens têm início com o debate estabelecido entre intelectuais, políticos e educadores paulistas que defendiam um tipo de escola primária que pretendia ser moderna e diferente daquela existente no Império: carente de edifícios, livros didáticos e mobiliário, precária em pessoal docente qualificado para o ensino de crianças e distante dos modernos métodos pedagógicos (Bencostta, 2009). Nesse sentido, para a recém-instalada República brasileira, a experiência inovadora das escolas primárias graduadas - ou grupos escolares, como vieram a ser denominados - foi entendida como um investimento que contribuiria para a consolidação de uma intencionalidade que procurava, por sua vez, esquecer a experiência do Império e apresentar um novo tipo de educação que pretendia ser popular e universal.

O Brasil se apoiou fortemente nas experiências americana e europeia de escolas graduadas ao propor uma nova modalidade de organização do ensino primário, interpretada como uma alternativa mais conveniente aos cofres do Estado por possuir qualidades pedagógicas e benefícios econômicos, tais como a melhor divisão do trabalho do professor e o aumento da oferta da instrução popular que atendesse a um maior número de crianças. Portanto, sintetiza Rosa Fátima de Souza, “as representações sobre a escola graduada buscavam articular o ideal da renovação do ensino com o projeto político de disseminação da educação popular aliado às vantagens econômicas" (Souza, 1998, p.44).

Segundo os estudos de Antonio Viñao sobre a escola graduada, esse tipo de organização implicava uma determinada ordenação do espaço, das atividades, dos ritmos e dos tempos, assim como uma distribuição de usos desses espaços e objetos, e uma classificação-valorização de professores e alunos, ou seja, não se tratava apenas de uma divisão horizontal e vertical do trabalho, mas, sobretudo, uma cultura ou modo de vida específico (Viñao, 1990, p.7). 
No contexto paranaense, quando Francisco Xavier da Silva, ao fim de mais um mandato como governador do Paraná (1900-1904), convidou o deputado estadual Cândido de Abreu - seu amigo pessoal e ex-secretário de Negócios de Obras Públicas em sua primeira governança, ainda no século XIX - para desenhar um grande edifício escolar, deu-lhe liberdade de criação tutelada, desde que a obra adotasse uma escala arquiteturológica funcional, mas também simbólica, que compusesse o conjunto de celebrações do Cinquentenário de Emancipação Política do Paraná (19 de dezembro de 1903). ${ }^{9}$ Nesse momento, temos, portanto, a interferência política no processo de concepção do edifício, definindo escala e estilo, o que nos reporta ao estudo de Carlos Ortega-Ibarra no qual "a arquitetura escolar é entendida como um ato técnico projetado por atores técnicos em circunstâncias históricas particulares” (Ortega-Ibarra, 2015, p.164). O fato de a concepção de um edifício ser conduzida por escolhas, intenções e decisões que admitem uma ideia ou remetem a ela nos autoriza a colocar em relação intelecto e produção material: "a ideia, em qualquer lugar, opera no mundo do arquiteto” (Boudon, 2001, p.18).

Mesmo não conseguindo cumprir o cronograma, o prédio em fase final de construção foi inaugurado na data cívica paranaense de 19 de dezembro de 1903. Esse edifício abrigaria o primeiro grupo escolar do estado (Figura 6), que não por mero acaso recebeu o nome de Dr. Xavier da Silva. ${ }^{10}$

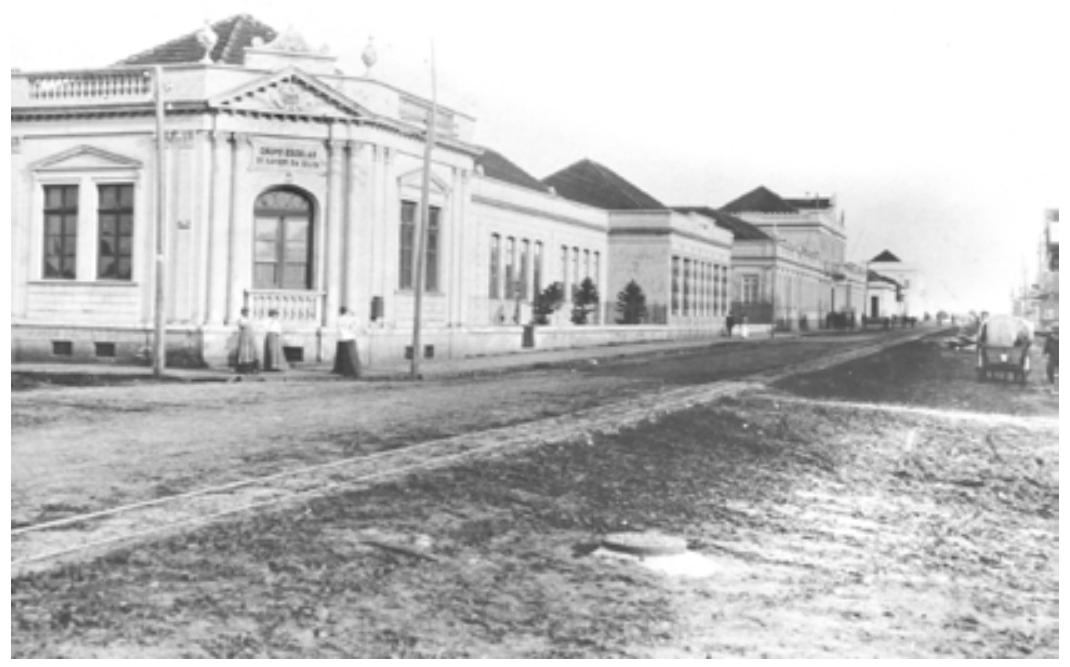

Figura 6 - Grupo Escolar Dr. Xavier da Silva Acervo: Casa da Memória/Curitiba. 
A escala arquiteturológica morfológica adotada por Cândido de Abreu no desenho dessa escola está expressa na sua forma monumental, em um eixo longitudinal paralelo às ruas Marechal Floriano Peixoto e Silva Jardim, que vislumbra a mesma escala simbólica empregada no Palacete Manoel Miró e na Casa das Ferraduras. O resultado é uma conveniente relação entre construção e terreno, que sobressai a ponto de registrar a imagem de um monumento que se consolidou na memória dos curitibanos ao longo das transformações urbanas.

Distante da opção Art Nouveau que Cândido de Abreu incorporará em 1914 no Paço Municipal, a morfologia aplicada no frontispício do edifício do Grupo Escolar Dr. Xavier da Silva é ornamentada, em especial, por um conjunto de elementos decorativos do neoclassicismo, contendo, em destaque, um medalhão em alto-relevo com a data de sua inauguração (1903), embutido na cornija de um típico frontão triangular, e as duplas de colunas coríntias que protegem a janela (Figura 7).

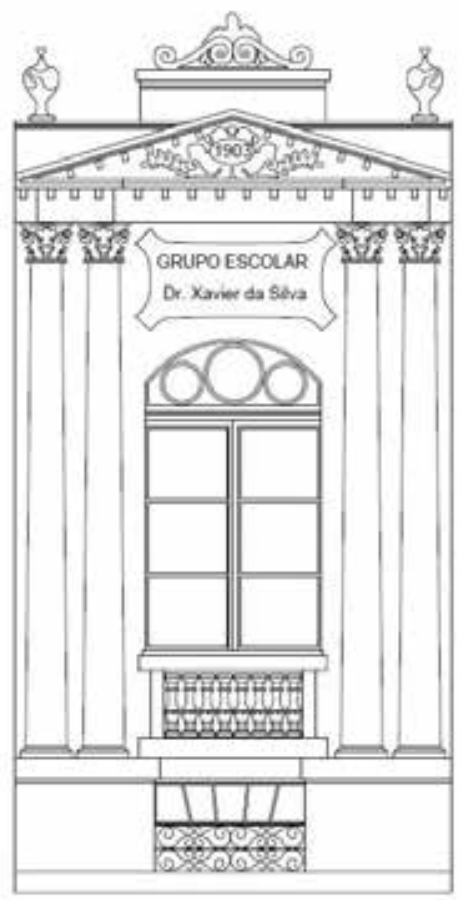

Figura 7 - Desenho do Frontispício do Grupo Escolar Dr. Xavier da Silva Acervo: Núcleo de Estudos e Pesquisas em História da Arquitetura Escolar (NEPHArqE/UFPR). 
Logo acima dela, a inscrição em relevo com o nome daquele estabelecimento de ensino. Observando as elevações laterais (Figuras 8 e 9) é possível examinar a estrutura dessa obra arquitetônica. O resultado harmonioso é decorrente, sobretudo, de sua simetria volumétrica e sua unidade de tratamento formal.

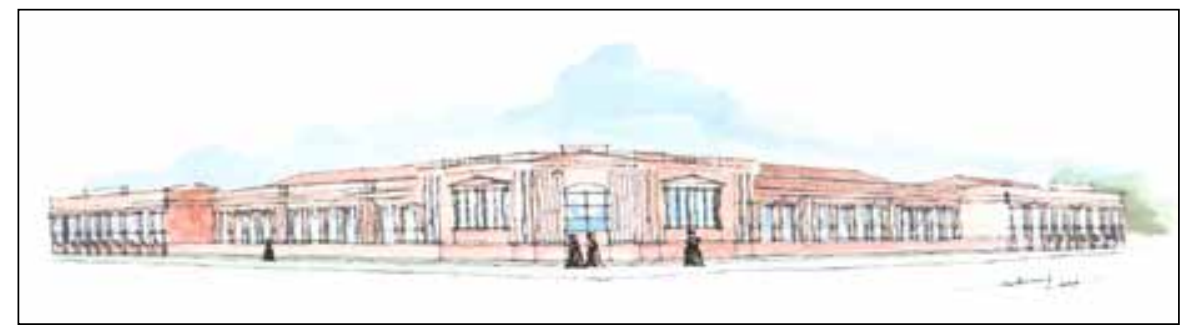

Figura 8 - Perspectiva do edifício do Grupo Escolar Dr. Xavier da Silva Acervo: Núcleo de Estudos e Pesquisas em História da Arquitetura Escolar (NEPHArqE/UFPR).

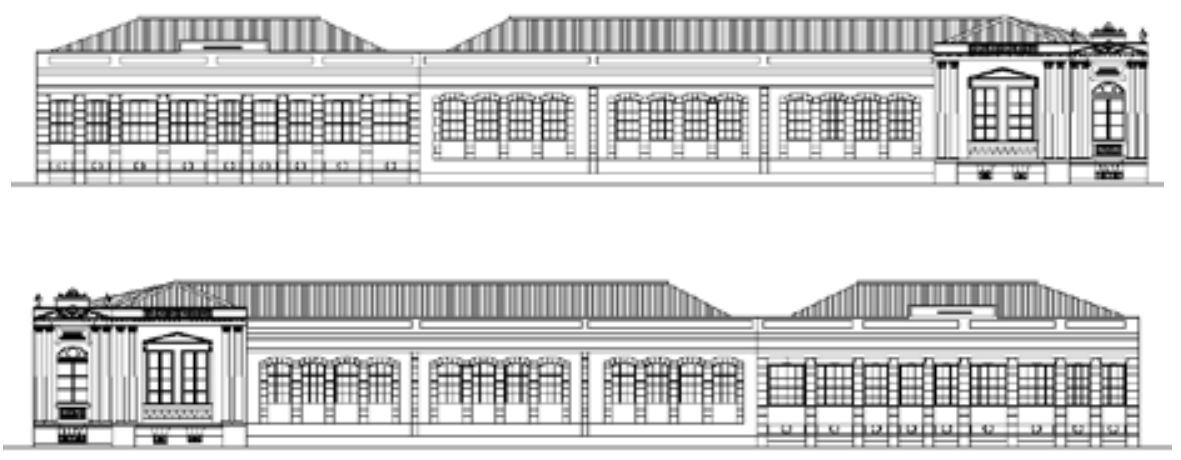

Figura 9 - Desenhos das elevações do edifício do Grupo Escolar Dr. Xavier da Silva Acervo: Núcleo de Estudos e Pesquisas em História da Arquitetura Escolar (NEPHArqE/UFPR).

Podemos inferir que quando pensou o espaço desse grupo escolar, Cândido de Abreu entendeu perfeitamente que para além de um local de ensino, ele deveria ser também um lugar de guarda das crianças que ali iam se alfabetizar sob a proteção do Estado. Portanto, não foi por mero acaso que o plano original arquitetônico em L estava voltado para o seu interior (Figura 10). ${ }^{11}$ 


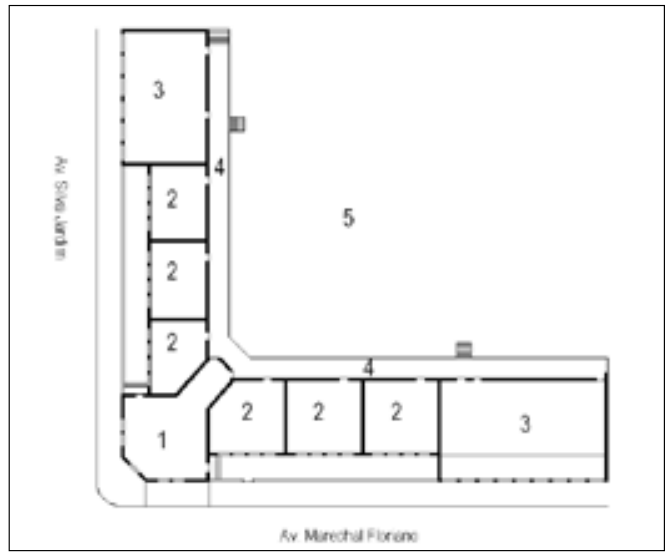

Figura 10 - Desenho da planta baixa do edifício do Grupo Escolar Dr. Xavier da Silva Acervo: Núcleo de Estudos e Pesquisas em História da Arquitetura Escolar (NEPHArqE/UFPR).

O plano indica na sua fachada, rente à rua, a função de resguardar o pátio interno em torno do qual estão interligadas as dependências do edifício. Esse jogo combinatório entre as salas, o vestíbulo, os pátios cobertos e o pátio externo colocam um limite à liberdade visual e espacial do observador externo. $\mathrm{O}$ vestíbulo que futuramente desempenharia a função de sala da direção da esco$1 \mathrm{l}^{12}$ é responsável por interligar os demais espaços internos. ${ }^{13}$ As salas de aulas e os pátios cobertos para as atividades de ginástica estavam rigorosamente separados por sexo: a ala masculina, localizada na face da rua Silva Jardim, mantinha distância segura da ala feminina, localizada na rua Marechal Floriano, e a passagem por onde circulavam os alunos, quando de sua entrada e saída da instituição, não escapava a essa lógica espacial e, muito menos, aos olhos dos adultos.

\section{Not AS FINAIS}

Questões acerca da importância da arquitetura como portadora e transmissora de mensagens de sentidos múltiplos não deixam de lado, evidentemente, os sujeitos que a projetaram, mas também a quem se destina: os primeiros receptores de seus significados e que fazem uso do espaço enquanto indivíduo-destinatário. 
A importância dos estudos acerca da arquitetura para a pesquisa histórica demonstra que a gramática espacial insere-se no tempo, assim como o edifício se insere em um espaço. Tempo e espaço dialogam com as transformações do tecido urbano e, mais proximamente, com as políticas e interesses que determinam sua construção. Por exemplo, no caso da arquitetura escolar, é preciso considerar como os discursos arquiteturais repercutiam diante das concepções de escola, pensados por arquitetos e autoridades de ensino, procurando, na medida do possível, verificar tipologias adotadas por certas correntes artísticas e culturais com o objetivo de identificar modos construtivos, elementos decorativos e programas iconográficos, e sua relação com os modos pedagógicos sobre o espaço escolar: "A participação dos arquitetos se fez presente no mundo da educação pelos diversos projetos de edifícios e casas destinados para fins de ensino, quer fossem eles escolas primárias, liceus, ginásios, escolas normais ou universidades" (Bencostta, 2013b, p.20).

Ao propor sua concepção teórica denominada arquiteturologia (architecturologie), Philippe Boudon (2003) leva-nos a pensar a arquitetura como pensamento do espaço da linguagem que expressa o conhecimento teórico da arquitetura. Por essa teoria entendemos que a criação dos projetos de Cândido de Abreu foi fortemente influenciada pela relação que ele estabeleceu entre a sua capacidade de compreensão dos modelos arquiteturais vigentes de sua preferência e as dimensões dos edifícios instalados no espaço real. Nessa perspectiva, consideramos que os espaços que ele projetou (residenciais, públicos e escolares) apresentam similitude à parte do espaço de concepção explicada e determinada pela modelização arquiteturológica, qual seja, é a arquiteturologia responsável por tornar visível a todos o espaço de concepção de modo que o edifício seja interpretado como resultado real de hipóteses, pensamentos e ideias decorrentes de seu contexto de criação, aquele onde é delimitada a experiência do objeto arquitetônico.

Ao tratarmos desse personagem da cena política paranaense e de seu desempenho como engenheiro e arquiteto, é preciso reconhecer que, de todas as suas atuações, aquela que menos contribuiu para torná-lo conhecido é a do projetista de uma arquitetura escolar. Se por um lado, enquanto autoridade do Estado, ele soube lidar com questões orçamentárias que destinavam recursos para o financiamento da educação, em especial, a construção de prédios escolares, por outro, esteve atento ao discurso de enaltecimento da educação republicana como estratégia de visibilidade das ações do governo. 


\section{FONTES}

A REPÚBLICA, 9 ago. 1906 e 18 set. 1912.

DIÁRIO OFICIAL DO PARANÁ, 17 mar. 2004.

GAZETA DO POVO, 13 jun. 2000.

DIÁRIO DA TARDE, 17 e 18 jan. 1916.

RELATORIO apresentado ao Exmo., Snr. Dr. Carlos Cavalcanti, Presidente do Estado do Paraná pelo Secretario d'Estado dos Negocios de Obras Publicas, Terras e Viação, Dr. Marins Alves de Camargo, Anno de 1913. Curytiba: Imprensa Paranaense, 1913.

RELATORIO apresentado ao Dr. José Pereira Santos Andrade, Governador do Estado do Paraná, pelo Engenheiro Civil Cândido Ferreira de Abreu, Secretario dos Negocios de Obras Publicas e Colonizasão, em 1 de setembro de 1896. Curytiba: Typ. A Vapor Modelo, 1896.

RELATÓRIO apresentado ao Governador do Estado do Paraná pelo Engenheiro Cândido Ferreira de Abreu, Secretario dos Negocios de Obras Publicas e Colonizasão, 1892.

TERMO de Encerramento dos Autos do Processo nº 03/2000, 11 de novembro de 2004. Curitiba: Coordenadoria do Patrimônio Cultural - Secretaria de Cultura do Estado do Paraná, 2004.

\section{REFERÊNCIAS}

BENCOSTTA, Marcus Levy. Arquitetura e espaço escolar: reflexões acerca do processo de implantação dos primeiros grupos escolares de Curitiba (1903-1928). Educar em Revista, Curitiba: Ed. UFPR, v.1, n.18, p.103-141, 2001.

. Arquitetura Escolar na Belle Époque: Jean Omer Marchand e Francisco de Paula Ramos de Azevedo (Montreal e São Paulo, 1894-1926). In: BENCOSTTA, Marcus Levy (Org.) Culturas escolares, saberes e práticas educativas: itinerários históricos. São Paulo: Cortez, 2007. p.103-128.

. Grupos escolares no Brasil: um novo modelo de escola primária. In: STEPHANOU, Maria; CAMARA BASTOS, Maria H. (Org.) Histórias e memórias da educação no Brasil (século XX). 3.ed. Petrópolis, RJ: Vozes, 2009. v.III, p.68-76.

Mobiliário escolar francês e os projetos vanguardistas de Jean Prouvé e André Lurçat na primeira metade do século XX. Educar em Revista, Curitiba: Ed. UFPR, v.1, n.49, p.19-38, 2013b.

- A noção de cultura material escolar em debate no campo de investigação da História da Educação. In: CASTRO, César A.; CASTELLANOS, Samuel L. V. (Org.) A escola e seus artefatos culturais. São Luís: Ed. UFMA, 2013a. v.1, p.21-34. 
BENCOSTTA, Marcus Levy. (Org.) História da educação, arquitetura e espaço escolar. São Paulo: Cortez, 2005.

.; VIDAL, Diana G. A historiografia da educação paranaense no cenário da história da educação brasileira: 10 anos de pesquisa na Universidade Federal do Paraná (1999-2008). Educar em Revista, Curitiba: Ed. UFPR, v.1, n.38, p.295-315, 2010.

BOUDON, Philippe. Enseigner la conception architecturale: cours d'architecturologie. Paris: Éd. de la Villette, 2001.

Sur l'espace architectural. Essai d'épistémologie de l'architecture. Nouvelle édition revue et augmentée. Marseille: Parenthèses, 2003.

CARNEIRO, David. Galeria de ontem. Curitiba: Vanguarda, 1963.

DICIONÁRIO Histórico-Bibliográfico do Estado do Paraná. Curitiba: Ed. Livraria do Chaim, 1991.

HOESNER JÚNIOR, Valério. Ruas e história de Curitiba. Curitiba: Artes \& Textos, 2002.

LEÃO, Ermelino de. Dicionário Histórico e Geográfico do Paraná. v.I. Curitiba: Instituto Histórico, Geográfico e Etnográfico Paranaense, 1994.

LE GOFF, Jacques. Memória-História. In: ENCICLOPÉDIA EINAUDI. v.1. Verbetes "Documento/Monumento". Lisboa: Imprensa Nacional-Casa da Moeda, 1984.

MENDONÇA, Naí N. Palacete da família Ascânio Miró. Casa da Memória, 1975. (Mimeo).

NORA, Pierre (Dir.) Les lieux de mémoire. Paris: Gallimard (Bibliothèque illustrée des histoires), Tome 1 - La République (1v., 1984), Tome 2 - La Nation (3v., 1986), Tome 3 - Les France (3v., 1992).

ORTEGA-IBARRA, Carlos. Historia Política de la Tecnología: una propuesta metodológica para la historia de la arquitectura escolar (Ciudad de México, 1880-1920). Revista Mexicana de Historia de la Educación, Ciudad de México, v.III, n.6, p.159180, 2015.

PÊCHEAUX, Michel. O discurso: estrutura ou acontecimento. Campinas, SP: Pontes, 1997.

RIZZI, Suzelle. Cândido de Abreu e a arquitetura de Curitiba entre 1897 e 1916. Dissertação (Mestrado em Teoria, História e Crítica da Arquitetura) - Universidade Federal do Rio Grande do Sul (UFRGS)/Pontifícia Universidade Católica do Paraná (PUC-PR). Porto Alegre/Curitiba, 2003.

SOUZA, Rosa F. Templos de civilização: a implantação da Escola Primária Graduada no Estado de São Paulo (1890-1910). Campinas, SP: Ed. Unicamp, 1998.

SUTIL, Marcelo S. O espelho e a miragem: moradia e modernidade na Curitiba do começo do século XX. Curitiba: Travessa dos Editores, 2009.

VIÑAO, Antonio. Inovación pedagógica y nacionalidad científica: la Escuela Graduada Pública en España (1898-1936). Madrid: Akal, 1990.

WESTPHALEN, Maria C. Avenida Cândido de Abreu. Estado do Paraná, 15 ago. 1959. 
Cândido de Abreu: projetos do primeiro urbanista da cidade de Curitiba do início do século XX

\section{NOTAS}

${ }^{1}$ Professor Titular da Universidade Federal do Paraná (UFPR), com atuação na Linha de História e Historiografia da Educação do Programa de Pós-Graduação em Educação. Coordenador do Núcleo de Estudos e Pesquisas em História da Arquitetura Escolar (NEPHArqE) e bolsista Produtividade em Pesquisa do CNPq. Pesquisa financiada com recursos do CNPq.

${ }^{2}$ Ramos de Azevedo iniciou sua experiência no mundo do trabalho em 1872, quando participou na condição de aprendiz na construção de ferrovias das Companhias Paulista e Mogyana de Estradas de Ferro, até partir para a Bélgica, em 1875, para realizar seus estudos superiores. De retorno ao Brasil, após alguns anos atuando em Campinas, estabelece na cidade de São Paulo o escritório F. P. Ramos de Azevedo e Cia., que, em pouco tempo, torna-se famoso, principalmente por ter em seu quadro jovens arquitetos e engenheiros que embelezaram aquela cidade e outras do interior paulista (BENCOSTTA, 2007, p.105).

${ }^{3}$ O Palacete Manoel Miró foi demolido na década de 1970 para construção de uma agência do Banco Bamerindus (extinto). Naquele local funcionou uma agência do Banco HSBC e, atualmente, sua posse pertence ao Banco Bradesco.

${ }^{4}$ Construído na mesma quadra da rua do palacete Ascânio Miró, o palacete Manuel Miró é uma edificação que foi demolida no século XX (cf. RIZZI, 2003).

${ }^{5}$ As janelas em formato de ferradura popularizaram o nome da residência de Cândido de Abreu.

${ }^{6}$ Cândido de Abreu projetou na Praça João Cândido o observatório astronômico e meteorológico da Faculdade de Engenharia da Universidade do Paraná. Essa obra, concluída em 1916, é tida por muitos como o mais genuíno exemplar de Art Nouveau de Curitiba (SUTIL, 2009).

${ }^{7}$ Com a última restauração do prédio, concluída em março de 2009, o Paço Municipal, que em épocas diferentes foi sede do Poder Legislativo com o Executivo, apenas Prefeitura e Museu Paranaense, é atualmente o Espaço Cultural Paço da Liberdade - Sesc Paraná.

${ }^{8}$ Janela saliente que se projeta para fora do edifício. Em arquitetura é comumente conhecida pela expressão inglesa bay window.

${ }^{9}$ As fontes que apontam a inauguração do prédio no final de 1903 não se contrapõem àquelas que confirmam sua entrega à comunidade no início de 1904, já na gestão do sucessor de Xavier da Silva, o governador Vicente Machado. De qualquer modo, o Grupo Escolar Dr. Xavier da Silva tornou-se o "embrião" dessa nova modalidade de ensino primário que seria implantada anos mais tarde em todo o estado do Paraná (cf. BENCOSTTA, 2001).

${ }^{10}$ Polêmicas acerca da localização do Grupo Escolar Dr. Xavier da Silva em bairro distante do centro da cidade (Rebouças) e do espaço escolar foram registradas em relatórios da própria administração pública. (cf. BENCOSTTA, 2005). 
${ }^{11}$ Anos mais tarde, a Secretaria de Obras Públicas autorizou a construção de mais uma ala na face da rua Marechal Floriano, modificando seu formato de L para U e tornando-a uma planta ainda mais fechada.

${ }^{12} \mathrm{O}$ diretor, além de ter suas funções administrativas, deveria ser o responsável por atualizar o corpo docente sobre os conteúdos discutidos nas escolas normais (cf. BENCOSTTA, 2009).

${ }^{13}$ No caso do Grupo Escolar Dr. Xavier da Silva, somente com a reforma do prédio, em 1913, parte do vestíbulo foi transformada em sala de direção (cf. RELATÓRIO, 1913).

Artigo recebido em 4 de novembro de 2015. Aprovado em 9 de dezembro de 2015. 